\title{
LEVANTAMENTO SOBRE EXCIPIENTES PARA CÁPSULAS EM FARMÁCIAS DE MANIPULAÇÃO DE CURITIBA
}

\section{SURVEY OF EXCIPIENTS FOR CAPSULES IN COMPOUNDING PHARMACIES IN CURITIBA}

\author{
FRAZON, Monique A. ${ }^{*}$; SILVESTRIN, Mayara S. ${ }^{2}$. \\ ${ }^{1}$ Farmacêutica, Pontifícia Universidade Católica do Paraná. \\ ${ }^{2}$ Farmacêutica, Pontifícia Universidade Católica do Paraná. \\ (e-mail: mo.frazon@gmail.com) \\ REC:05/2010 AC:06/210
}

\begin{abstract}
RESUMO
Os fármacos raramente estão sozinhos na formulação, e sim acompanhados dos excipientes. Os excipientes contribuem tanto para a facilidade de formulação quanto para estabilidade do fármaco. Devido à grande importância na formulação, este trabalho foi voltado a análise de como algumas farmácias de Curitiba utilizam excipientes para alguns fármacos que requerem cuidado especial. Os resultados demonstraram que a média de acerto na utilização os excipientes não ultrapassou os $40 \%$ e que um estudo mais profundo por parte das farmácias é necessário.
\end{abstract}

Palavras-chave: excipientes, cápsulas, manipulação.

\begin{abstract}
The drugs are rarely alone in the formulation, but together with the excipients. The excipients contribute both to ease the formulation as long as drug stability. Due to the great importance in the formulation, this study was aimed at analyzing how some pharmacies in Curitiba use excipients for some drugs that require special care. The results showed that the average accuracy when using the excipients did not exceed $40 \%$ and a deeper study by the pharmacies is required.
\end{abstract}

Keywords: excipients, capsules, manipulation.

\section{INTRODUÇÃO}

Os fármacos encapsulados raramente são administrados isoladamente, normalmente vêm acompanhados de excipientes. Estas substâncias são produtos auxiliares diretamente envolvidas na composição das diversas formulações farmacêuticas. Embora historicamente os excipientes tenham sido considerados inertes, já que não exercem ação terapêutica ou biológica na forma farmacêutica, hoje são vistos como capazes de influenciar a velocidade e/ou a extensão da absorção de um fármaco. Constituintes de diferentes sistemas terapêuticos viabilizam o sucesso da forma farmacêutica final, apresentando características e propriedades diferentes daquelas pertinentes aos fármacos. Excipientes farmacêuticos constituem elementos de elevado destaque na formulação dos medicamentos, uma vez que, exercem efetivo papel na garantia de obtenção da forma farmacêutica adequada ao uso e ao efeito terapêutico desejado, regendo e influenciando de maneira significativa a cedência do princípio ativo contido no medicamento (AULTON ,2005). 
O fármaco e os excipientes utilizados devem ser compatíveis entre si para gerar um produto estável, eficaz, atraente, fácil de administrar e seguro. Como alguns fármacos têm características especiais físico-químicas e de compatibilidade deve-se selecionar os excipientes adequados a eles (ANSEL; POPOVICH; ALLEN, 2000).

Nosso trabalho será voltado à análise de como algumas farmácias magistrais de Curitiba, Paraná, utilizam os excipientes na manipulação das cápsulas para alguns medicamentos que requerem cuidados especiais, pois devido a esses adjuvantes 0 fármaco pode ou não exercer sua ação, variando o tempo de liberação, e biodiponibilidade, e consequentemente a sua eficácia.

\section{MATERIAL E MÉTODOS}

Foi realizada uma pesquisa sobre a utilização dos excipientes para cápsulas com farmacêuticos de 50 farmácias magistrais de Curitiba, Paraná, escolhidos aleatoriamente, por meio de uma lista telefônica. Os dados foram coletados no período de novembro de 2008 a março de 2009 , através do preenchimento de um questionário contendo 10 medicamentos e mais de 20 excipientes, no qual o farmacêutico marcava com um X no(s) excipiente(s) que utilizava para o referido medicamento. Para a análise dos resultados foram instituídos pontos, que variam de zero a dois, para cada farmácia em cada fármaco, sendo 0 (zero) para excipientes totalmente errados para o fármaco em questão; 1 (um) para combinação aceitável de excipientes, mas não a mais indicada e 2 para combinação ideal de excipientes para o fármaco. Os fármacos de escolha foram cuidadosamente selecionados de acordo com interações prejudiciais fármaco-excipiente e também outras alterações que o fármaco pode sofrer, relacionadas à utilização ou não dos adjuvantes e que interferem farmacologicamente e farmacocineticamente na sua ação. $O$ trabalho foi realizado dentro dos padrões exigidos pelo comitê de ética em pesquisa da Pontifícia Universidade Católica do Paraná.

\section{RESULTADOS E DISCUSSÕES}

Das 50 farmácias nas quais foram entregues os questionários, apenas 28 responderam. Algumas farmácias não existiam mais, outras eram filiais de alguma farmácia que já havia respondido, mas o fator principal para diminuição do número de questionários respondidos foi a recusa por parte do farmacêutico responsável.

Os resultados dos 28 questionários foram analisados. A pontuação total em cada farmácias varia de 0 (zero), onde há erro em todos os fármacos, a 20 (vinte), se todos os fármacos estiverem com seus excipientes ideais. Para facilitar a amostra de resultados, foi expresso em porcentagem, já que nem todas as farmácias manipulavam os 10 fármacos, variando então o resultado de zero (zero) a 100\% (cem), colocados na figura 1. 


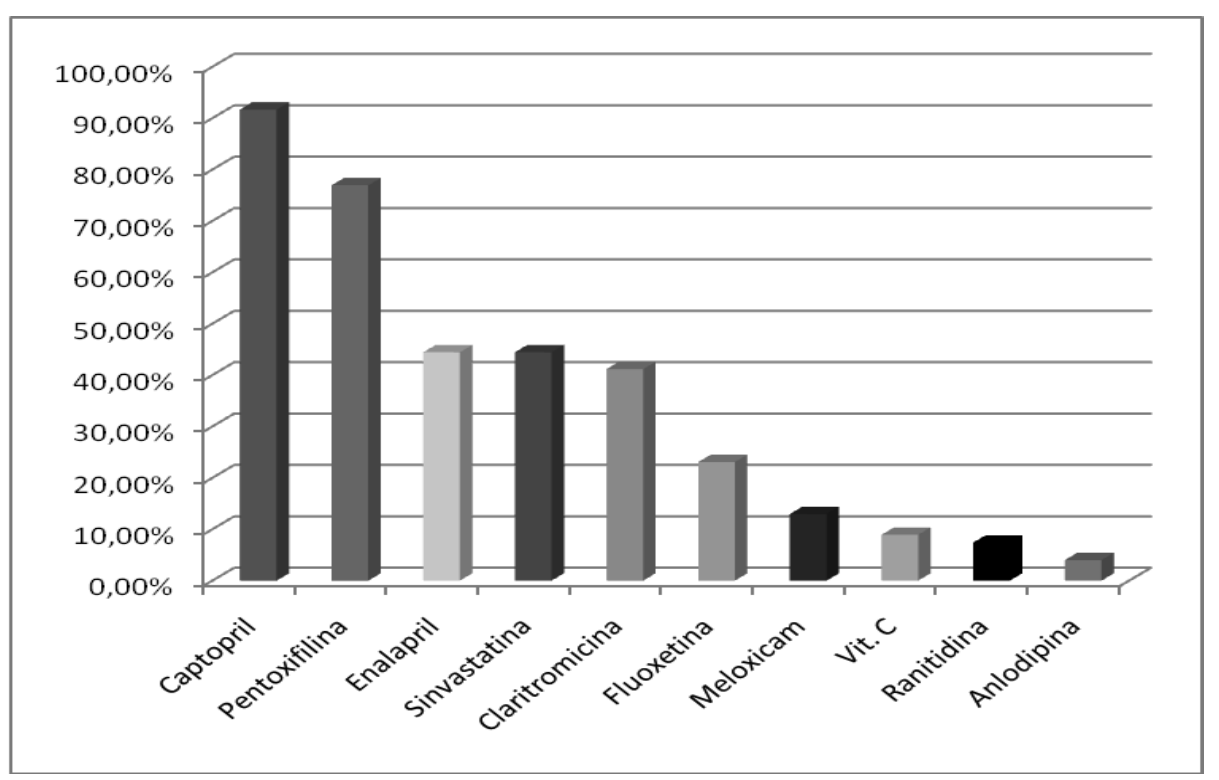

Figura 1. Utilização correta dos excipientes por fármaco.

De acordo com Silva (2006) a anlodipina é uma droga antagonista do cálcio que, em sua formulação, necessita de um início de ação mais lento e um efeito mais prolongado. Para obter tal efeito, deve-se adicionar fosfato de cálcio dibásico, diminuindo então a velocidade de absorção deste fármaco. Além disso, pela ação abrasiva do fosfato de cálcio dibásico adiciona-se um lubrificante, como o estearato de magnésio a $1 \%$, e um desintegrante, glicolato sódico de amido. Ainda com função de retardar a absorção, a celulose microcristalina acima de $20 \%$, e o amido pelo efeito diluente devem ser usados. Por ser um fármaco moderadamente higroscópico, necessita de um absorvente como o dióxido de silício coloidal, na concentração de 1 a $10 \%$ (FERREIRA, 2008).

Segundo a pesquisa, a anlodipina obteve apenas $4 \%$ de acerto na utilização do excipiente correto nas farmácias. Esse foi o menor índice encontrado entre todos os fármacos. O fosfato de cálcio dibásico foi o principal agente de erro, pois apenas quatro das 25 farmácias que manipulam a anlodipina o utilizava. Contribuem ainda para o alto erro a não utilização de um lubrificante em $36 \%$ das farmácias.

O captopril, um fármaco inibidor da enzima conversora de angiotensina, precisa da adição de um excipiente absorvente, como o dióxido de silício, pois em meio aquoso está sujeito a oxidação e liberação de odor sulfuroso. Deve-se adicionar também na fórmula um diluente, para facilitar a manipulação, como o manitol ou a celulose microcristalina acima de $20 \%$. Para melhorar a fluidez dos pós, um lubrificante como o amido pode ser adicionado. Não se recomenda utilizar o estearato de magnésio com captopril, pois há a possibilidade de ocorrência de interação entre eles (FERREIRA, 2008).

Como porcentagem de acerto no uso de excipientes para o captopril obteve-se o dado de $91,66 \%$, sendo o maior percentual de acerto entre os fármacos avaliados. Provavelmente esse fato ocorreu devido à facilidade dessa formulação, que exige apenas excipientes absorventes, diluentes e um lubrificante. Estes excipientes são comumente empregados nas formulações de vários fármacos, para facilitar a manipu- 
lação, diminuir a perda do fármaco e ainda garantir a estabilidade da formulação por absorver a água e evitar oxidação, como no caso. Dentre os $8,34 \%$ de erro, o mais comum foi a não utilização do excipiente absorvente e ainda a utilização do estearato de magnésio, que como dito anteriormente, interage com o captopril.

Segundo Silva (2006), a claritromicina é um antibiótico macrolídio que inibe a síntese protéica bacteriana pela ligação à subunidade $50 \mathrm{~S}$ dos ribossomos de microorganismos sensíveis.

A sua solubilidade é aumentada com a diminuição do $\mathrm{pH}$ do meio gástrico. Apresenta hidrofobia mesmo em $\mathrm{pH}$ ácido, por isso requer um solubilizante como a povidona. O polissorbato, excipiente molhante, deve ser adicionado para também para diminuir a hidrofobia, diminuindo a tensão superficial. Porém, com adição de agentes solubilizantes a solubilidade desse fármaco aumenta muito e a meia-vida torna-se relativamente curta, portanto devem-se usar excipientes insolúveis como amido ou celulose microcristalina. Além disso, utiliza-se um absorvente, como o dióxido de silício, um lubrificante, um conservante, o ácido sórbico e ainda um diluente como o talco, para garantir estabilidade à formulação (FERREIRA, 2008).

Para a claritromicina, a porcentagem entre as farmácias, com relação à utilização dos excipientes corretos, foi de $41,17 \%$. O erro mais comum encontrado na formulação foi a não utilização do agente molhante em $26 \%$ das farmácias, seguido da não utilização de excipientes insolúveis em seis das 16 farmácias que manipulavam o fármaco em questão.

O maleato de enalapril é um pró-fármaco que precisa na formulação a adição do bicarbonato de sódio para aumentar o pH e formar o enalaprilato de sódio, sua forma ativa (SILVA, 2006).

Como diluente e absorvente compatível com o enalapril, pode-se utilizar a celulose microcristalina e/ou dióxido de silício coloidal, a lactose também pode ser utilizada nesse caso. Para finalizar a fórmula, adiciona-se um lubrificante, como o estearato de magnésio e um surfactante, como o lauril sulfato de sódio, $2 \%$, como agente molhante para aumentar a dissolução e biodisponibilidade do fármaco (FERREIRA, 2008).

O enalapril obteve porcentagem de acerto de 44,44\%. Esse resultado é preocupante visto que o enalapril é um anti-hipertensivo amplamente utilizado (MINISTÉRIO DA SAÚDE, 2008).

O principal erro nessa formulação foi a não utilização do bicarbonato de sódio. Das 27 farmácias que manipulavam esse fármaco, apenas 11 utilizavam o excipiente alcalinizante. Outro erro importante nessa formulação foi a não utilização do lauril sulfato de sódio por $40,74 \%$ das farmácias.

A fluoxetina é um antidepressivo inibidor da recaptação da serotonina de meiavida longa, muito similar aos antidepressivos tricíclicos clássicos, porém usada em doses menores que estes (SILVA, 2006).

$\mathrm{Na}$ atualidade, a fluoxetina é o agente antidepressivo mais prescrito, por isso a grande importância em sua preparação (STULZER, 2006).

Nesse preparo não deve ser utilizado, juntamente com a fluoxetina, o talco, o carbonato de cálcio, óxido de magnésio e outros excipientes que retardam a absorção desse fármaco no organismo. O estearato de magnésio pode interferir negativamente sobre as propriedades biofarmacotécnicas da fluoxetina pelo fato de que este forma uma película hidrofóbica envolvendo as partículas do fármaco, o que pode acabar dificultando a dissolução do fármaco, e consequentemente sua absorção. A lactose 
também não deve ser utilizada, pois reage com o grupo amino primário desse antidepressivo, resultando em produtos de cor amarronzada, devido à condensação do tipo Maillard, sendo então incompatível com esta droga (FERREIRA, 2008).

A fluoxetina também é incompatível com o manitol. Como diluentes e absorventes compatíveis com a fluoxetina, pode-se utilizar a celulose microcristalina a $20 \%$ e o aerosil. Para finalizar a fórmula, adiciona-se o simeticone 1 a $2 \%$, que além de lubrificante, diminui o principal efeito adverso da fluoxetina, a flatulência (KIBBE, 2000).

Para esse antidepressivo, o índice de acerto na formulação dos excipientes corretos foi $23,07 \%$. Pela grande importância, tanto na ação quanto na grande utilização desse fármaco, o valor encontrado nas farmácias que participaram da pesquisa é preocupante. Os erros na formulação incluem a utilização de estearato de magnésio como lubrificante em 15 das 26 farmácias que manipulavam essa droga, a utilização de lactose e manitol em 3,8\% das farmácias e ainda a utilização do talco farmacêutico em $15,4 \%$ das farmácias. Esses excipientes, como já dito, interagem de alguma maneira com a fluoxetina, prejudicando, retardando ou até anulando sua ação no organismo, e, portanto não devem ser utilizados. O óxido de magnésio foi o único excipiente incompatível com esse antidepressivo que não foi utilizado por nenhuma farmácia. O simeticone, um lubrificante e ainda uma alternativa para a flatulência gerada pelo fármaco foi utilizado em apenas $7,7 \%$ das farmácias.

De acordo com Silva (2006) o meloxicam é um antiinflamatório derivado do ácido enólico.

Para garantir a estabilidade da formulação com este antiinflamatório é necessária a adição do citrato de sódio dihidratado a 1\%, que tem ação tamponante, para dar resistência à formulação contra a mudança do $\mathrm{pH}$ gerado pelo fármaco, que no caso tem caráter ácido. Para completar a formulação, adiciona-se um lubrificante, para facilitar o escoamento dos pós, diluentes como a celulose microcristalina e o amido, e ainda um absorvente (FERREIRA, 2008).

No caso desse antiinflamatório, a porcentagem de erro na formulação foi de $87,04 \%$ dentre as farmácias pesquisadas. O componente principal, o citrato de sódio dihidratado e outros da mesma classe foram utilizados em apenas $12,96 \%$ das farmácias participantes desse estudo.

A pentoxifilina é uma droga com ação hemorreológica, ou seja, modifica a flexibilidade eritrocitária, a adesão e a agregação plaquetária, consequentemente reduzindo a viscosidade sanguínea e melhorando a circulação periférica. É metabolizada pelo fígado em metabólicos ativos que chegam a ficar em concentração plasmática de 5 a 8 vezes maior que a pentoxifilina (SILVA,2006).

A adição de excipientes que permitam uma liberação prolongada reduz a incidência de efeitos colaterais hipotensores. Para tal efeito, necessita da ação de um adjuvante formador de matriz hidrofílica, que retarda a liberação e absorção do fármaco por aumentar a viscosidade do meio, como a hidroxipropilmetilcelulose a $40 \%$. Para finalizar a formulação, adiciona-se um lubrificante e ainda um diluente (FERREIRA, 2008).

A pentoxifilina foi o fármaco menos manipulado entre as farmácias pesquisadas, apenas 13 das 28 farmácias. Mesmo assim, a porcentagem de acerto na formulação foi uma das mais altas encontradas nessa pesquisa, 76,92\%. A hidroxipropilmetilcelulose, principal excipiente utilizado neste caso, é importantíssima, como dito anteriormente, para retardar a liberação da pentoxifilina e consequentemente, diminuir os 
efeitos colaterais.

A ranitidina é um fármaco que reduz a secreção ácida gástrica pela ação antagonista seletiva do receptor H2 da histamina (SILVA, 2006).

Por ser facilmente oxidável pela luz, deve ser adicionado um antioxidante á formulação como o BHT e ainda utilizar para frascos escuros e ao abrigo da luz (AULTON, 2005).

A ranitidina também é higroscópica, necessitando de um absorvente, sendo o dióxido de silício o mais utilizado, na concentração de $1 \%$. Para finalizar a formulação, adiciona-se um diluente, podendo ser o amido ou celulose microcristalina (FERREIRA, 2008).

Apesar de muito manipulada e conhecida dentre as farmácias, a ranitidina obteve $92,6 \%$ de erro na utilização dos excipientes corretos. O principal erro encontrado foi a não utilização de um excipiente antioxidante por 26 das 28 farmácias pesquisadas.

Sinvastatina é uma droga hipolipidêmica que tem como mecanismo básico a inibição da ação da enzima hidroximetilglutaril coenzima $A$ redutase que regula a produção do colesterol intracelular no hepatócito. É muito importante no tratamento das dislipidemias e consequentemente doenças como infarto agudo do miocárdio, acidente vascular encefálico, angina do peito, entre outras doenças determinadas, na maioria das vezes, pela aterosclerose (SILVA, 2006).

$\mathrm{Na}$ sua formulação, pelo fato de ser facilmente oxidável a luz, deve conter um antioxidante como o $\mathrm{BHA}$ e uso de recipiente adequado e que fique ao abrigo da luz. Ainda deve ser adicionado o manitol, pois este é um adjuvante diluente não higroscópico, importante para fármacos sensíveis a umidade como a sinvastatina e também o dióxido de silício coloidal, excelente absorvente. O estearato de magnésio associado ao manitol melhora o fluxo, facilitando e manipulação. Ainda pode-se adicionar outro diluente, como o amido (FERREIRA, 2008).

No caso dessa droga o erro encontrado da utilização dos excipientes foi de $55,56 \%$. A não utilização de agente antioxidante ocorreu em 46,15\% das farmácias. Outros erros incluem a não utilização de um excipiente absorvente e também do manitol.

A vitamina $\mathrm{C}$ ou ácido ascórbico, também conhecido como fator antiescorbútico, é uma das principais vitaminas, em função do importante papel que desempenha na fisiologia humana. Atua na síntese do colágeno, na respiração celular, no metabolismo de aminoácidos, na ativação de enzimas, na absorção do ferro, na defesa do organismo contra infecções e toxiinfecções e ainda na síntese de hormônios corticosteróides (SILVA, 2006).

Esta vitamina é incompatível com o amido, pois este excipiente se complexa com drogas ácidas, como o ácido ascórbico, o que pode alterar as propriedades farmacológicas do fármaco. Além disso, necessita de um antioxidante, pois sem este ocorre redução lenta da vitamina $\mathrm{C}$, gerando um enegrecimento da mistura. Para finalizar, adiciona-se um diluente como a celulose microcristalina ou ainda o manitol (MATTOS, 2006).

Apesar de ser considerada de simples preparo, apenas 8,92\% das farmácias conseguiram utilizar os excipientes ideais para a vitamina $\mathrm{C}$. Alguns erros incluem a utilização do amido em 21 das 28 farmácias e ainda a não utilização de um agente antioxidante por $10,71 \%$ das farmácias pesquisadas. 
O dióxido de silício, excipiente absorvente, foi utilizado por mais de $80 \%$ das farmácias pesquisadas, sendo o adjuvante mais comum na pesquisa.

$\mathrm{O}$ acerto na pesquisa, por farmácia, foi indicada na figura 2. Três das 28 farmácia utilizaram excipientes considerados errados ou não utilizaram excipientes essencias para nenhum dos 10 fármacos. Apenas três farmácias acertaram mais de $50 \%$ do questionário e nenhuma farmácia obteve $100 \%$ de acerto, sendo o maior índice de $65 \%$ obtido por duas farmácias apenas.

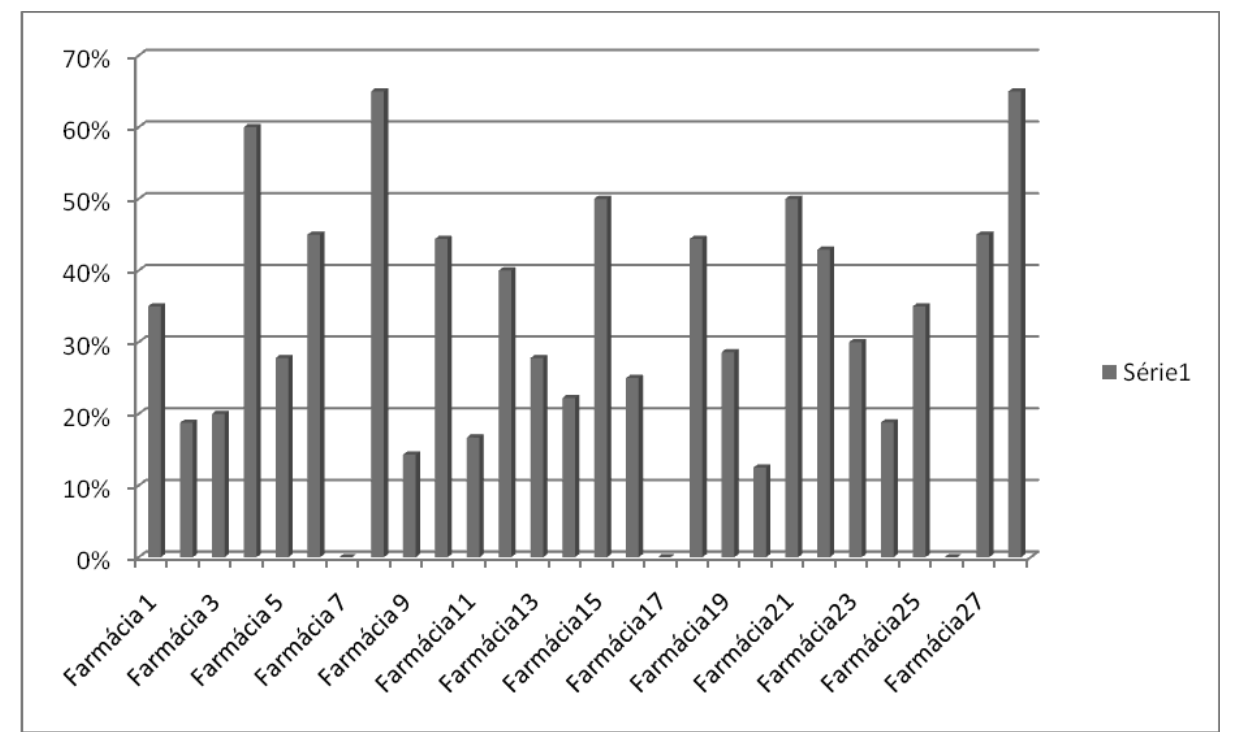

Figura 2. Utilização dos excipientes corretos por fármaco

\section{CONCLUSÃO}

Como no presente estudo, as farmácias magistrais eram livres para participar ou não da pesquisa, não se pode ter uma média geral para Curitiba, e somente das farmácias que aceitaram responder. Pelo fato de que os questionários foram entregues em uma data e recolhidos uma semana após, não há como afirmar a veracidade das respostas. Seria necessário um estudo com um número maior de entidades participantes e de modo em que se possa pessoalmente verificar qual excipiente utilizado.

Dentre as farmácias analisadas obteve-se um resultado abaixo do satisfatório, a média de acerto foi de $36 \%$. O excipiente aerosil foi utilizado em todos os fármacos pesquisados em mais de $80 \%$ das farmácias e o amido foi utilizado em todos os fármacos por mais de $60 \%$ das farmácias. Tal fato pode ser justificado pelo baixo custo de ambos, e pela pouca possibilidade de interação com fármacos, cuja exceção clara é a vitamina $\mathrm{C}$.

O óxido de magnésio, polissorbato, povidona e ácido sórbico não foram utilizados por nenhuma farmácia, devido a sua baixa popularidade e por serem de utilização mais específica, somente seria utilizado caso as farmácias analisadas tivessem um estudo mais aprofundado, e também pelo custo que gera a farmácia ter de comprar uma quantidade mínima do fornecedor para usar baixa concentração no excipiente de pouquíssimos fármacos. $O$ fato da não aplicação destes revela a falta de pesquisa 
específica por fármaco.

No geral, a atenção maior ficou voltada para o fato de que a maioria das farmácias avaliadas ainda não utiliza alguns dos excipientes mais indispensáveis e muitas delas ainda utilizam excipientes que tem algum tipo de incompatibilidade com o fármaco, comprometendo a ação farmacológica o que é o fato mais preocupante.

Constatamos que existe uma necessidade urgente de adequação para excipientes e fármacos pesquisados e concluímos que o cuidado e o conhecimento na seleção dos excipientes a serem misturados com os fármacos encapsulados levam à garantia de maior efetividade do produto manipulado.

\section{REFERÊNCIAS}

AGÊNCIA NACIONAL DE VIGILÂNCIA SANITÁRIA (ANVISA). Denominações comuns brasileiras: glossário. Disponível em: http://www.anvisa.gov.br/medicamentos/dcb/glossario.pdf. Acesso em: 10 fev. 2009.

ANSEL,Howard C; POPOVICH, Nicholas G.; ALLEN, Loyd V. Farmacotécnica: Formas Farmacêuticas \& Sistemas de Liberação de Fármacos. 6 ed. Premier, 2000

AULTON, Michael E. Delineamento de formas farmacêuticas. 2. ed. Porto Alegre: Artmed, 2005.p.256-262 e 453-476.

DÄRR, Alfred. Tecnología farmacéutica: texto para el ingeniero farmacéutico. Zaragosa: Acribia, 1981. p.53-66

Farmacopéia portuguesa. 7.ed. Lisboa: Infarmed. 2002. CD-ROM.

FERREIRA, Anderson de Oliveira. Guia Prático da Farmácia Magistral. Juiz de Fora, 2008. p. 96-139. v.1.

KIBBE, Arthur H. Handbook of Pharmaceutical Excipients. 3.ed. Washinton D.C.: American Pharmaceutical Association \& Pharmaceutical Press. 2000.

MATTOS, Rubia Mara B. Barcelos. Revisão de Literatura Sobre Excipientes de Utilização em Cápsulas. 2006. 82 f. Trabalho de conclusão de curso (Especialização em Farmácia Magistral) - Pontifícia Universidade Católica do Paraná, Curitiba, 2006.

MINISTÉRIO DA SAÚDE. Textos básico de saúde. Brasília, 2008. Disponível em: < http://www.saude.gov.br/bvs>. Acesso em: 20 mar. 2009.

SILVA, Penildon. Farmacologia. 7. ed. Rio de Janeiro: Guanabara, 2006. p.349460;680-686;1000.

STULZER, Hellen Karine et al. Avaliação da compatibilidade entre a fluoxetina e excipientes usados na fabricação de cápsulas pela farmácia magistral, Florianópolis, v.7, n.1, 2006. 